\title{
EM DEFESA DE UMA CONCEPÇÃO MULTICULTURAL DOS DIREITOS HUMANOS
}

IN SUPPORT TO A MULTICULTURAL CONCEPTION OF HUMAN RIGHTS

\author{
Patrícia Pires Badke*
}

RESUMO: Neste artigo, criticaremos a visão ocidental universalizante dos direitos humanos apresentada por alguns autores diante de uma realidade global composta por diversas culturas e tradições que apresentam diferentes costumes e valores. Dessa maneira, defende-se uma ideia multicultural dos direitos humanos, em que se leva em consideração a realidade história das diversas nações para buscar uma tolerância e um reconhecimento mútuo por meio de um possível diálogo.

PALAVRAS-CHAVE: Direitos Humanos. Direitos Fundamentais. Multiculturalismo. Universalidade. Diálogo.

ABSTRACT: In this article we criticize the occidental view of human rights as universal rights, presented by some authors in a global reality compound by different cultures and traditions, which present distinct customs and values. By this reason, we support the idea of having multicultural human rights, that consider the historical reality of the nations aiming to search for tolerance and mutual recognition through a possible dialogue.

KEYWORDS: Human Rights. Fundamental Rights. Multiculturalism. Universality. Dialogue.

* Mestre em Direito das Relações Internacionais pelo Centro Universitário de Brasília (UniCEUB). Atua como Assessora do Chefe da Missão na Embaixada do Sultanato de Omã no Brasil. (patricia.badke@gmail.com) 


\section{INTRODUÇÃ̃O}

O presente artigo pretende analisar os direitos humanos de um ponto de vista multicultural. Cada nação nasce e se desenvolve em uma tradição, com determinados valores a priori de qualquer questionamento. Desse modo, é muito difícil impor a todas as diferentes culturas e tradições a ideia atual de direitos humanos, por alguns pensadores pretendida como universal. Além disso, essa ideia de direitos humanos, frequentemente discutida e analisada, é apenas uma visão ocidental, que nem sempre vai de acordo com pensamentos orientais, por exemplo. Questionaremos a possibilidade de se continuar acreditando na existência de direitos humanos universais, em um período pós-globalização, em que o choque das culturas seria inevitável.

Dessa maneira, primeiramente serão analisadas as semelhanças e as diferenças entre conceitos frequentemente discutidos, como direitos fundamentais e direitos humanos. Assim, com um pouco mais de clareza em relação a esses conceitos, é que será proposta a análise dos direitos humanos e sua proteção em um mundo multicultural e, consequentemente, as dificuldades enfrentadas.

Cabe acrescentar que tanto as violações quanto as lutas em defesas dos direitos humanos apresentam uma decisiva dimensão nacional e que as atitudes perante os direitos humanos assentam-se em pressupostos culturais específicos. Pode-se, então, defender a ideia de que a política dos direitos humanos é, basicamente, uma política de cunho cultural. Dessa forma, ao falar de cultura é falar de diferenças, de fronteiras, de particularismos. Portanto, ficaria contraditório tratar os direitos humanos como universais e multiculturais simultaneamente.

Ademais, caso se conclua que o conceito de direitos humanos universais é apenas um conceito ingênuo e simplista, que não mais deveria ser utilizado, existirá ainda a necessidade de se propor uma nova ideia para a aceitação dos direitos humanos como algo relativo à tradição em que está inserido.

Portanto, esse trabalho apresentará uma nova ideia para a aceitação dos direitos humanos como algo relativo à tradição em que o ser humano está inserido. Essa nova proposta traz o conceito de tolerância, abordado por Bobbio (2002), para o campo dos direitos humanos, acreditando ser útil para uma compreensão destes direitos em diferentes povos.

\section{DIREITOS FUNDAMENTAIS E DIREITOS HUMANOS}

Uma questão sempre presente quando se trata de direitos humanos é a tentativa de separar e conceituar direitos humanos e direitos fundamentais, buscando uma diferenciação. Por meio de constantes pesquisas acerca do tema, não fica muito claro a diferenciação de ambos os conceitos. O que fica talvez subjetivo, e aqui nos arriscaríamos a sugerir, é que a expressão "direitos fundamentais" é constantemente abordada quando 
se trata dos "direitos humanos" previstos na legislação de cada país, ou seja, a tutela nacional dos direitos e garantias fundamentais do homem, previstos na Constituição de cada país. Contudo, a expressão "direitos humanos" é frequentemente utilizada em um âmbito mais global, buscando significar direitos de qualquer indivíduo independentemente de qualquer contexto histórico, geográfico, ou seja, buscando a igualdade plena dos seres humanos.

Conforme Queiroz (2002), o princípio fundamental da ordem jurídica dos direitos fundamentais não é o "postulado da unidade dos direitos e deveres fundamentais", mas o da prevalência dos direitos fundamentais sobre os deveres fundamentais. Se assim não fosse, afirmar-se-ia, ao invés, uma relação de identidade. Estaríamos então, segundo ela, em presença de um sistema totalitário ou, no mínimo, autoritário, isto é, um regime não constitucional.

Neste sentido, fala-se hoje na multifuncionalidade dos direitos fundamentais, querendo com isso aludir aos diferentes elementos, funções e dimensões desses direitos e liberdades no seu conjunto. Uma diferenciação que, um pouco mais tarde, Alexy designará por "direitos fundamentais na sua totalidade", isto é, na totalidade das suas múltiplas compreensões e dimensões jurídico-funcionais (QUEIROZ, 2002, p. 68).

A autora afirma ainda:

A proteção dos direitos fundamentais vem agora garantida pelos tribunais, e em particular pelos tribunais de justiça constitucional, sendo portanto a estes que caberá, em último termo, a delimitação jurídico-funcional e a coordenação dessas esferas de liberdade e pretensão em caso de conflito prático. (QUEIROZ, 2002, p. 104)

Ainda tratando de direitos fundamentais, podemos citar Perez Luño (2005, p. 286), que considera os direitos fundamentais como valores, princípios e normas. Ele explica que no plano constitucional, os direitos fundamentais aparecem positivados por meio dos sistemas: o da lex generalis ou de cláusulas gerais e o da leges speciales ou casuístico, métodos que, por sua vez, podem se combinar em um sistema misto, que é o mais frequentemente utilizado nas Constituições. No sistema de cláusulas gerais, os direitos fundamentais aparecem consagrados em forma de valores ou princípios, enquanto no sistema de leis especiais ou casuístico se positivisam como normas específicas que se tornam concretas ao alcance dos distintos direitos básicos.

Entretanto, a classificação dos direitos fundamentais apresenta ainda constantes problemas. Assim, cabe procurar estabelecer a classificação desses direitos, de acordo com as características jurídicas que neles se manifestam. De acordo com Ferreira Filho (2005, p. 103), de um modo geral, essas características estão ligadas à geração em que eles surgem reconhecidos.

No entanto, tecnicamente nem sempre assim é. "Há direitos fundamentais que não apresentam os caracteres da sua geração, mas de outra, seja que a antecipem, seja 
que sua consagração se haja retardado." Entretanto, essa tarefa oferece diversas dificuldades graves. A principal delas é que muitos direitos fundamentais têm mais de uma fase. $\mathrm{O}$ autor explica os tipos de classificações dos direitos fundamentais frequentemente abordadas, porém não entraremos nesta questão neste trabalho.

Segundo o autor Carrió (1990, p. 24), o conceito de direitos humanos, qualquer que seja a melhor fundamentação, se apresenta analisado em diversos contextos de inter-relação e oposição. Estão referidos mediantes pares de noções tais como: a) indivíduo ou grupo de indivíduos versus Estado; b) grupos minoritários dissidentes versus ortodoxias políticas, religiosas, ideológicas e sociais; c) indivíduos ou grupos minoritários dissidentes versus grupos de pressão não oficiais, organizados e poderosos (meios de comunicação massivos, agrupações de empresários, sindicatos de empregados, partidos políticos), etc. Em cada um desses âmbitos de oposição aparecem prerrogativas ou pretensões de indivíduos ou grupo de indivíduos que se apresentam como direitos não renunciáveis que correspondem a seus titulares pela simples razão de serem indivíduos ou agrupações de indivíduos.

A ordem jurídica das comunidades desenvolvidas e progressistas contém normas e instituições que definem e protegem as prerrogativas e pretensões citadas anteriormente. É o que chamamos de tutela nacional dos direitos humanos, ou ainda dos direitos fundamentais, criada com o constitucionalismo do bills of rights. Assim, ao examinar outros focos de problemas relacionados com a proteção destes direitos, veremos que, durante a segunda metade deste século, foi possível assistir a uma nova consagração e tutela dos direitos humanos, pretendida internacional, vinculada ao desenvolvimento do direito internacional público.

Os problemas enfrentados na definição quanto ao que seriam os direitos humanos são inúmeros, como previamente abordado. Portanto, para tentar solucionar esses problemas, é fundamental primeiramente distinguir com clareza dois tipos de família de direitos humanos. Essa distinção não afeta a unidade do conceito genérico de direitos humanos, ambos os tipos de família são igualmente considerados direitos humanos.

Por um lado, temos o direito a que a comunidade organizada (o Estado) ou parte dela (grupos de pressão de diversos tipos) não interfiram além de certos limites no âmbito da liberdade dos seres humanos, concebidos seja individualmente ou em formas de grupos. Essa família de direitos humanos será a de interesse nos estudos apresentados neste trabalho. Estes direitos são característicos das ordens políticas que imprecisamente são denominadas Estados liberais. A soma dos conteúdos desses direitos coincide com o primeiro conceito de liberdade, ou seja, o conceito de liberdade negativa defendido por Berlin (1969), que será abordado mais a frente.

Essa primeira família de direitos humanos não deve ser confundida com um segundo tipo de família, segundo o qual o desenvolvimento integral do ser humano exige que a comunidade organizada atue positivamente, a fim de criar condições necessárias 
para o gozo eficaz de certos direitos. Ou seja, esse segundo tipo de família se vincula com sistemas políticos que não se limitam a garantir áreas de liberdade frente a interferências alheias. Dessa forma, se vinculam com estruturas do Estado que imprecisamente podemos caracterizar com a expressão: Estado de Direito.

Com definições um pouco mais claras sobre direitos fundamentais e direitos humanos, é possível seguir o trabalho para então chegar a uma proposta em defesa da concepção multicultural dos direitos humanos.

\section{A LIBERDADE E OS CONFLITOS ENTRE OS SERES HUMANOS}

Nesta parte, serão usados como base os conceitos de Berlin (1969, p. 2), em que o autor diz não acreditar que todos os movimentos históricos ou conflitos entre seres humanos são redutíveis a movimentos ou conflitos de ideias ou forças espirituais e nem mesmo são efeitos destes. Ele acredita que para entender movimentos históricos ou conflitos entre humanos, é preciso, primeiramente, entender as ideias e as atitudes envolvidas neles, o que faz esses movimentos parte da história humana e não meros eventos naturais. Neste contexto, o autor apresenta a questão central da política, que trata de obediência e de coerção e tenta-se trazer respostas para os conflitos entre os seres humanos.

Ao dizer que coagir um homem é privá-lo da liberdade, propõe analisar dois sensos de liberdade centrais, envolvidos em um contexto histórico para explicar os conflitos. Primeiramente, apresenta a noção negativa de liberdade em que analisa a área dentro da qual a pessoa ou o grupo poder ser ou fazer o que puder ou quiser, sem a interferência de outras pessoas. Em seguida, apresenta a noção de liberdade positiva, em que analisa a fonte de controle ou interferência que possa determinar alguém a fazer ou ser uma coisa ao invés de outra. (BERLIN,1969, p. 2)

Segundo Berlin, Kant identifica a liberdade não como uma eliminação de desejos, mas sim como uma resistência a eles e, principalmente, como o controle destes desejos. Dessa maneira, nos identificamos como o controlador e escapamos de sermos controlados. Somos livres por sermos autônomos. Obedecemos às leis, mas as impusemos ou as encontramos em nós mesmos. Liberdade é obediência, mas nas palavras de Rousseau, obediência a uma lei a qual prescrevemos a nós mesmos. A liberdade individual proposta por Kant vai além do domínio da causalidade natural. (1969, p. 11-12)

Ainda de acordo com o autor, Locke diz que onde não há lei, não há liberdade, pois a lei racional é a direção aos próprios interesses dos seres humanos ou a expectativas gerais. Montesquieu, ao esquecer seus momentos liberais, trata de liberdade política não como a permissão de fazer o que queremos, ou até mesmo o que a lei permite, mas sim como o poder de fazer o que deveríamos querer, o que é também repetido por Kant. Ele acredita que quando o indivíduo abandonar por completo sua forma selvagem de 
liberdade sem lei, para reencontrá-la em um estágio de dependência de acordo com a lei, isso será a verdadeira liberdade, em que para essa dependência é o trabalho do próprio desejo atuando como legislador. Liberdade, por ser incompatível com autoridade, se torna praticamente idêntica a ela. Esse é o pensamento e a linguagem de todas as declarações do Século XVIII de direitos do homem, e de todos que buscam uma sociedade construída conforme as leis racionais do legislador sábio, ou da natureza, ou da história, ou do ser supremo (1969, p. 17-18).

Fichte diz que ninguém tem direitos contra a razão. O homem teme subordinar sua subjetividade às leis da razão. Ele prefere tradição ou arbitrariedade. Porém, ele necessita ser subordinado. É verdade que Kant insistiu, seguindo Rousseau, que a capacidade para se autodirigir racionalmente pertenceu a todos os homens; e não pode existir especialistas in questões morais, visto que a moralidade foi uma questão não de conhecimento especializado, mas do uso correto de uma habilidade universal do ser humano; e, consequentemente, o que fez o homem livre não foi o ato de autoimprovisações, o qual poderia ser coagido a fazer, mas sim o fato de saber o que se gosta de fazer, o que ninguém poderia fazer em favor de outrem.

Mas mesmo Kant, quando começou a lidar com questões políticas, reconheceu que nenhuma lei poderia possivelmente privar os seres humanos de sua liberdade racional. Contudo, se o ser humano falha em se autodisciplinar, alguém precisa fazê-lo para ele sem que este reclame de falta de liberdade. $O$ fato de o julgamento racional de Kant tê-lo enviado à prisão deixa evidente que o "réu" não seguiu os próprios interesses racionais, e assim como uma criança, um selvagem ou um ignorante, não está maduro para se autogovernar.

A extensão da liberdade individual ou de um grupo em escolher viver como desejam precisa ser ponderada contra as reivindicações de outros valores, dos quais igualdade, justiça, felicidade, segurança ou ordem pública sejam talvez os principais exemplos. Por essa razão, não pode ser ilimitada.

Ao final, o homem escolhe entre valores máximos, escolhe como agir por ter sua vida e pensamentos determinados por categorias morais fundamentais e conceitos que são parte de sua existência e própria identidade, parte do que o torna humano. De fato, o grande desejo por garantias de que nossos desejos sejam eternos e seguros talvez seja, a necessidade de nossas certezas de infância ou de valores absolutos do nosso passado primitivo. (BERLIN, 1969, p. 31-32)

\section{DIREITOS HUMANOS, SUBJETIVIDADE E INTERPRETAÇÃO}

Trataremos primeiramente da subjetividade dos direitos humanos. Quando se elege o homem, individualmente ou em grupo, como sujeito ativo e titular dos direitos humanos, aparece inexoravelmente a subjetividade, ou a personalização, ou a 
individualização da titularidade. Se os direitos são do homem, e se o homem é seu sujeito titular ou ativo, nada impede responder positivamente à questão quando à subjetividade dos direitos humanos, porque se subjetivam na pessoa humana.

$\mathrm{O}$ direito subjetivo, e neste trabalho entenda-se os direitos do homem como inclusos nesta categoria, é algo próprio do homem: faculdade, pretensão, atribuição, possibilidade de exigir uma conduta, opção para fazer ou omitir, permissão, disponibilidade, etc. Podemos exemplificar os direitos à vida e à saúde, o direito ao trabalho e de trabalhar, o direito a se locomover e à liberdade física, o direito à jurisdição, à propriedade. Todos esses direitos humanos, entre outros, são subjetivos, no sentido em que são direitos do homem. Contudo, em cada um é preciso ter a precaução de entender bem seu conteúdo e significado, tanto como a prestação do sujeito passivo que lhe da satisfação (BIDART CAMPOS, 2006, p. 17-18).

Assim, uma vez que com múltiplas variedades de qualificativos, os direitos humanos foram expressos como: direitos do homem, direitos naturais do homem, direitos da pessoa humana etc., e foram considerados inerentes à natureza do homem, ou primários, ou até mesmo fundamentais. Neste contexto, é possível questionar a universalidade dos direitos humanos nas diversas tradições.

A universalidade dos direitos humanos quer significar que eles são devidos ao homem, individualmente e em grupos, ou seja, em todos os Estados. Todavia, é preciso considerar a situação histórica, temporal e espacial que envolve a convivência desses homens, nestes Estados. A exigência do valor não traça limites setoriais, nem quanto a espaços territoriais, nem quanto a âmbitos humanos, mas se acomoda em ambientes históricos que se circunscrevem de forma geográfica e populacional. A forma de realização dos direitos exigidos pelo valor é, por própria natureza e vocação histórica do mesmo valor, variáveis e dependentes das situações sociopolíticas e jurídicas.

A universalidade se assimila com a igualdade de todos os homens em qualquer tempo e lugar, por isso, necessita-se enfatizar a relevância das circunstâncias históricas neste conceito. Entretanto, é necessário também separar se nessas circunstâncias existe a fantasia de propor que a então realidade histórica, com seus ingredientes de tempo e espaço, está ausente na forma de criar a encarnação dos direitos em cada situação cultural.

Trataremos neste momento da palavra cultural. Vem muito bem ao caso, o porquê de a realização dos valores ser uma obra de cultura humana, e por fim, de valores de justiça e os que por debaixo deste valor integram o plexo axiológico jurídicopolítico. E as obras de cultura se marcam temporal e espacialmente no mundo dos homens, e se realizam com sujeição ao conhecimento progressivo que eles alcançam na revelação dos valores, ou seja, o descobrimento desses valores e seus critérios, assim como em função das possibilidades e impossibilidades que surgem não somente do conhecimento do valor, mas também de toda a complexa rede de marcos, fatores 
e pressupostos que os cientistas políticos analisam e dão por concorrentes em todo regime ou sistema político.

Assim, os direitos humanos deveriam ser vistos desde seus pontos de vista filosóficos, como dependentes para sua realização das condições existentes no campo próprio cultural em questão. Para esclarecer, mesmo que pareça possivelmente um mau jogo de palavras, os mesmos direitos humanos que se pretendem universais, eternos, supratemporais, etc., podem adquirir e, aqui se acredita que adquirem, diversos e distintos modos de criações em cada situação histórica, em cada época, em cada lugar, em cada Estado, para cada sociedade e para cada cultura.

As valorações sociais, as representações coletivas, as crenças, as ideias e tudo que compõe o que chamamos de complexo cultural ou tradição de cada sociedade possuem história, tempo e espaço. Os valores e seu dever ser ideal valem e existem em todos os contextos temporais e espaciais para todos os homens.

A liberdade e os direitos do homem são situacionais, ou seja, estão em situação. E a situação, cada qual, se dá no tempo e no espaço, em uma convivência que depende do seu entorno e que transcorre entre homens concretos, instalados em uma situação, a sua própria. (BURDEAU, 1975, p.34).

Não precisamos ir muito longe para verificar os diversos modos de criação que os direitos humanos fundamentais adquirem dependendo de cada situação. É neste contexto que utilizaremos a interpretação dos direitos fundamentais no âmbito interno para exemplificar as dificuldades da universalização de alguns conceitos. Segundo Häberle (1997) o conceito de interpretação reclama um esclarecimento que pode ser assim formulado:

Quem vive a norma acaba por interpretá-la ou pelo menos por co-interpretá-la. Originariamente, indica-se como interpretação apenas a atividade que, de forma consciente e intencional, dirigese à compreensão e à explicitação de sentido de uma norma (de um texto). A utilização de um conceito de interpretação delimitando também faz sentido: a pergunta sobre o método, por exemplo, apenas se pode fazer quando se tem uma interpretação intencional ou consciente. (HÄBERLE, 1997, p. 13-14).

Para o autor, a própria interpretação dos direitos fundamentais em uma Constituição pode ser relativizada. Ele trata da relativização da interpretação jurídica assentada em algumas razões por ele apresentadas. Primeiramente, explica que o juiz constitucional já não interpreta, no processo constitucional de forma isolada: muitos são os participantes do processo. Além disso, na posição que antecede a interpretação constitucional "jurídica" dos juízes, são muitos os intérpretes, ou, melhor dizendo, todas as forças pluralistas públicas são, potencialmente, intérpretes da Constituição (HÄBERLE, 1997, p. 41).

Perez Luño também aborda as peculiaridades da interpretação dos direitos fundamentais e, assim como Häberle, trata da relativização. $\mathrm{O}$ autor cita Forsthoff e seus 
trabalhos precisos sobre a interpretação jurídica e a hermenêutica dos direitos fundamentais. Desse modo, ele explica que para Forsthoff, quando a interpretação dos direitos fundamentais deixa de ser uma atividade jurídica com base em normas, para converter-se a uma tarefa filosófica de intuição de valores, o próprio processo interpretativo perde sua racionalidade e evidencia, e ainda ameaça a proposta da Constituição (PEREZ LUÑO, 2005, p. 284).

Portanto, a discussão quanto às dificuldades de interpretação dos direitos fundamentais nas Constituições nacionais não é nenhuma novidade e é assim, tema do trabalho de inúmeros autores. Para Ferrara (1940, p. 21), a atividade interpretativa é a operação mais difícil e delicada a que o jurista pode dedicar-se, e reclama fino tato, senso apurado, intuição, muita experiência e domínio perfeito não só do material positivo, como também do espírito de uma legislação.

Utilizamos estes exemplos apenas para fazer uma analogia e reforçar a dificuldade de acreditar que os direitos humanos possam ser considerados universais. Se no âmbito nacional, as regras já não são igualmente aplicadas porque dependem da interpretação de um sujeito que possui seus valores, no âmbito internacional é ainda mais difícil acreditar que inúmeras culturas e tradições possam ter as mesmas crenças e acreditar nos mesmos valores. Com essas bases e reflexões é possível seguir adiante com o objetivo inicial do presente trabalho.

\section{UMA DEFESA LIBERAL DO MULTICULTURALISMO}

Neste ponto, convém dizer algumas palavras a respeito de uma versão da defesa liberal do multiculturalismo, levada a cabo por Raz (1996, p. 170-191). O autor propõe uma defesa do multiculturalismo e do direito à identidade dos grupos culturais sobre a base de dois princípios centrais: a) a ideia liberal da centralidade das condições para a seleção de modos de vida, por exemplo, do exercício da liberdade de eleição, como objetivo e valor fundamental da ética política e; b) a ideia da inevitabilidade do pluralismo cultural, segundo a qual, todas as culturas, mesmo as que resultam incompatíveis entre elas, têm igual valor intrínseco e não existe um critério objetivo para julgá-las segundo regras de superioridade e inferioridade.

Raz, ao colocar o exercício da liberdade como centro de sua argumentação em favor do multiculturalismo, o professor de Oxford conclui afirmando que a pertinência a um grupo cultural faz possível a prosperidade cultural e material, as relações interpessoais e a própria identidade. Mais adiante, escreve que a opressão frustra sistematicamente a habilidade das pessoas, ou dos grupos de pessoas para realizar ou dar expressão nesta sociedade, a um aspecto importante de sua natureza (1996, p.184).

Isso significa, claramente, que o respeito pelo multiculturalismo e os direitos dos grupos culturais terminam-se fundamentando, segundo Raz, não apenas no exercício da autonomia, mas também em certas dimensões da natureza humana. 
Acerca dessas considerações sobre a problemática estabelecida pela existência de diferentes culturas, em talvez uma mesma comunidade política, vale analisar, mesmo que apenas a questão ética e jurídica, que se estabelece frente à pretensão de intervir em outras nações de diversas culturas majoritárias, argumentando a violação dos direitos humanos em sua ordem política interna. Alguns autores liberais, entre outros, John Rawls, elaboraram complexas argumentações para justificar essa possibilidade (CORREAS, 2008, p. 100).

Rawls (2001) refere-se a uma concepção política particular de direito e justiça, que se aplica aos princípios e normas do Direito e da prática internacional. Ele utiliza o termo "sociedade dos povos" para designar todos os povos que seguem os ideais e os princípios do Direito dos Povos nas suas relações mútuas. Esses povos têm os próprios governos internos, que podem ser democráticos, liberais e constitucionais ou governos não liberais, mas decentes.

A ideia de justiça de Rawls (2001, p. 3-5) baseia-se no conceito de família de contrato social, e o processo seguido antes que os princípios de direito e justiça sejam selecionados e acordados é, de certa maneira, o mesmo no caso nacional e no internacional. $\mathrm{O}$ autor discute como o Direito dos Povos preenche certas condições que justificam chamar a Sociedade dos Povos de utopia realista. "Uma sociedade dos povos é razoavelmente justa no sentido de que os seus membros seguem o Direito dos Povos razoavelmente justo nas suas relações mútuas.

Os direitos humanos no Direito dos Povos expressam uma classe especial de direitos urgentes, tais como a liberdade que impede a escravidão ou servidão, a liberdade de consciência e a segurança de grupos étnicos contra o assassinato em massa e o genocídio. A violação dessa classe de direito é igualmente condenada por povos liberais razoáveis e por povos hierárquicos decentes. Rawls (2001, p. 103) afirma que os direitos humanos desempenham um papel especial em um Direito dos Povos razoável, pois restringem as razões justificadoras da guerra e põem limites à autonomia interna de um regime. Dessa forma, refletem as duas mudanças básicas e historicamente profundas em como os poderes da soberania têm sido concebidos desde a Segunda Guerra Mundial.

Os direitos humanos são distintos dos direitos constitucionais ou dos direitos de cidadania democrática liberal, ou de outros direitos que são próprios de certos tipos de instituições políticas, individualistas e associativas. Eles estabelecem um padrão necessário, mas não suficiente, para a decência das instituições políticas e sociais. Ao fazê-lo, limitam o Direito nacional admissível de sociedades com boa reputação em uma Sociedade dos Povos razoavelmente justa. (RAWLS, 2001, p. 103)

Em o Direito dos Povos, Rawls passa a explicar quais são as funções dos direitos humanos, que ele reduz a três: Seu cumprimento é condição necessária da decência das instituições políticas de uma sociedade e da sua ordem jurídica; Seu cumprimento é 
suficiente para excluir a intervenção justificada e coercitiva de outros povos, por exemplo, por meio de sanções diplomáticas e econômicas ou, em casos graves, da força militar; Eles estabelecem um limite para o pluralismo entre os povos. E, finalmente, ao extrair suas conclusões definitivas, o filósofo de Harvard efetua uma declaração especialmente pertinente. Escreve acerca do que se pode chamar de fundamentos filosóficos dos direitos humanos. Ele explica que apesar do nome, os direitos humanos constituem uma classe especial de direito que se explica por sua função em uma concepção liberal do direito dos povos, aceitável pelas sociedades bem ordenadas, tanto liberais como hierárquicas. Este é o esquema central da argumentação rawlsiana acerca dos fundamentos do direito e da ética internacional.

\section{UMA CONCEPÇÃO MULTICULTURAL DOS DIREITOS HUMANOS}

As revoluções francesa e americana reconheceram de modo contundente os direitos humanos. Pode-se dizer que foram o ponto final de um longo processo doutrinal e normativo tendentes a este reconhecimento e, sem dúvida, também o ponto de partida de múltiplos novos desafios.

Se nos concentrarmos somente nos últimos quarenta anos, cabe afirmar que a globalização trouxe, entre outras coisas, maior mobilidade geográfica, aumentando a imigração e incrementando à diversidade em cada Estado. Paralelamente, o mesmo fenômeno da globalização produziu um incremento exponencial da comunicação e dos intercâmbios econômicos e culturais.

Este fato fez surgir um maior contato entre modelos culturais heterogêneos e seu estabelecimento e se resulta admissível colocar à prova os limites da heterogeneidade. Contudo, além dos problemas concretos, o certo é que surgiu um debate teórico com consequências práticas indubitáveis e relevantes: ao reconhecerem-se os direitos, passou a existir uma questão sobre seu caráter universal.

O questionamento da universalidade dos direitos é um questionamento da teoria dos direitos. O problema se encontra, sem dúvida, com outro problema ainda mais profundo: o da conexão entre direito e moral. Existem razões para sustentar que a universalidade dos direitos apenas pode fundamentar-se em uma moral universal. É aí exatamente que existe um conjunto de problemas para determinar até que ponto a moral de diferentes estados condiciona o êxito de uma política de direitos.

Com base em textos de Richard Bernstein e Hans-Georg Gadamer, pretende-se, neste trabalho, estudar uma concepção multicultural dos direitos humanos. Ou seja, os direitos humanos como algo dependente da tradição e da cultura dos povos em questão.

As discussões apresentadas por Bernstein (1983, p. 126) quanto à universalidade da racionalidade e quanto à incomensurabilidade de coisas diferentes que não podem ser comparadas por critérios comuns são fundamentais ao serem transportadas para o 
estudo dos direitos humanos. Em uma passagem do texto, o autor citado diz não ser possível, ao ser humano, se livrar de sua história por um ato de vontade, uma vez que a tradição está inserida nas pessoas. E o reconhecimento destas tradições é condição necessária para a existência de um diálogo entre elas.

Neste contexto, a hermenêutica apresentada em Bernstein (1983) pode ser o caminho para uma concepção multicultural dos direitos humanos. A questão da hermenêutica é uma forma de ser no mundo, ou melhor, para se relacionar com as pessoas, ou até mesmo com as diferentes culturas, envolve-se necessariamente a compreensão. É neste ponto que Gadamer (1993, p. 344) possui grande influência e relevância nos estudos da hermenêutica. $O$ autor afirma que os preconceitos são a condição da compreensão e explica como são a todos os momentos aplicados.

Gadamer (1993) brilhantemente introduz a fusão de horizontes como forma de compreensão, que é o movimento que permite ir e vir na tradição histórica, em uma fusão com o presente. Para ficar mais claro, a fusão de horizontes proposta pelo autor é tudo aquilo que resiste à compreensão, podendo ser o próprio horizonte de uma tradição do passado fundindo com o presente, como também, o horizonte de uns fundindo com o de outros que pensam de forma diferente.

Assim como Gadamer, este trabalho acredita que a tradição é um conjunto de possibilidades em que cada ser absorve-a de uma maneira diferente. Porém, há de considerar que a tradição é algo coletivo e compartilhado, portanto devidamente ligada à sociedade. Trazendo esse conceito ao tratar de direitos humanos, fica nítida a importância de se levar em conta as diferentes tradições como fontes de verdade. Afinal, acredita-se que a verdade tem a ver com uma atualização de uma tradição no presente. Assim, ela é impossível de se controlar por ser imprevisível, podendo mudar a qualquer momento.

De acordo com Bernstein (1983, p. 46), todos os defensores da hermenêutica, ou mais genericamente da tradição humanística, tiveram de confrontar as reivindicações persistentes de que apenas a ciência é a medida da realidade, do conhecimento e da verdade. Para ele, o conhecimento precisa ser objetivo, ou então é apenas um pseudoconhecimento. "Quando se entram os valores, estes precisam ser tratados como respostas emocionais não cognitivas ou preferências subjetivas práticas”.

Da mesma maneira, Perez Luño (2005, p. 310) aborda os problemas específicos da interpretação e aplicação do que chama de direitos fundamentais. Ele diz que os direitos fundamentais representam uma das decisões básicas do constituinte por meio da qual os principais valores éticos e políticos de uma comunidade alcançam expressão jurídica. Visto que, como anteriormente indicado no texto, os direitos fundamentais 
demonstram o horizonte de metas sociopolíticas a se alcançar, ao tempo que se estabelece a posição jurídica dos cidadãos em suas relações com o Estado, ou entre si. Esta peculiaridade dos direitos fundamentais incide em sua interpretação e exige que seu significado seja entendido unitariamente, ou seja, como um sistema entre cujos elementos não pode existir antíteses ou contradições de orientação e sentido.

\section{CONCLUSÃO}

Os direitos humanos são, sem dúvida, um marco nas relações internacionais há séculos. Apresentam papel fundamental na relação entre Estados e são também a melhor forma de proteção internacional da pessoa humana. Além disso, podemos ainda acrescentar que os direitos humanos servem também para permitir o diálogo internacional e até mesmo nacional, por ser um objeto de interesse comum, mesmo que não exatamente aplicado da mesma forma.

Todavia, é de extrema relevância considerar que existem inúmeras tradições e culturas em todo o mundo com costumes, crenças e credos religiosos diversos. Assim, conceituar os direitos humanos pode ser mais complicado que parece em um primeiro momento.

Podemos dizer que essa temática já enfrenta dificuldades desde sua conceituação quanto ao que seriam os direitos humanos, até mesmo se estes podem ou não serem considerados universais, ou seja, aplicados em todas as tradições da mesma maneira e com os mesmos valores.

Não seríamos ingênuos em reduzir todas as complexidades deste tema apenas a estas duas questões. Porém, não é possível, neste artigo, discutirmos toda a problemática dos direitos humanos no multiculturalismo. Portanto, nos restringiremos apenas à questão inicial do texto. Será que ainda podemos aceitar os direitos humanos como universais? Esta resposta está longe de ser definitiva e ainda pretende-se desenvolver uma fundamentação mais objetiva e concreta.

Mesmo assim, em um primeiro momento, pode-se dizer que é praticamente impossível acreditar que, em um mundo de tanta diversidade, é possível conceituar algo tão complexo como universal. Até porque temos de concordar que para os direitos humanos serem considerados como universais necessitariam atender às necessidades de todas as inúmeras tradições existentes.

Sustenta-se, neste trabalho, a proposta apresentada por Bobbio (2002), em defesa da tolerância e tenta-se transportar essa ideia para o campo dos direitos humanos. Em outras palavras, conforme Bobbio, a tolerância passou a ser um significado positivo quando deixou de ser considerada como uma mera regra de prudência. Foi preciso que 
a liberdade de fé ou de opinião, assegurada por uma correta aplicação da regra da tolerância, passasse a ser reconhecida como a melhor condição para fazer que, mediante a persuasão e não a imposição, triunfe a verdade em que se crê.

Não está dito, porém, que todos possam compartilhar esta convicção otimista na força expansiva da verdade. Todavia, ainda que tal convicção não seja universalmente compartilhada, abre-se a estrada para uma nova razão, ainda mais profunda e eticamente imperiosa, com que se pode defender o princípio de tolerância: o respeito pela consciência alheia. Essa razão baseia-se no princípio universalmente reconhecido pelas nações civis nas declarações dos direitos nacionais e internacionais: o direito à liberdade de consciência. (BOBBIO, 2002, p.151)

Assim, transportando essa ideia para o campo dos direitos humanos e acreditando que cada povo tem sua liberdade de consciência fundamentada na tradição em que nasceu e se desenvolveu, o princípio da tolerância pode ser considerado um meio para compreender os direitos humanos em suas diferentes formas. Acredita-se que todas as ideias devem ser toleradas, e neste contexto a hermenêutica pode, quem sabe, ser o caminho para a compreensão dos direitos humanos multiculturais, com base no princípio da tolerância.

\section{REFERÊNCIAS}

BERLIN, Isaiah. Two Concepts of Liberty. In: BERLIN, Isaiah. Four essays on liberty. Oxford: Oxford University Press, 1969.

BERNSTEIN, Richard J. Beyond objectivism and relativism: science, hermeneutics and praxis. Philadelphia: University of Pennsylvania Press, 1983.

BIDART CAMPOS, Germán J. Teoría general de los derechos humanos. Buenos Aires: ASTREA, 2006.

BOBBIO, Norberto. Elogio da serenidade e outros escritos morais. São Paulo: Editora UNESP, 2002.

BURDEAU, Georges. Democracia: ensaio sintético. Lisboa: Publicações Europa-América, 1975. BROWN, Wendy; WILLIAMS, Patrícia. La crítica de los derechos. Bogotá: Siglo Del Hombre Editores, 2003.

CARRIÓ. Genaro R. Los derechos humanos y su proteccion: distintos problemas. Buenos Aires: Ed. Abeledo-perrot, 1990.

CIANCIARDO, Juan. (Org.). Multiculturalismo e universalismo de los derechos humanos. Buenos Aires: Ad-Hoc, 2008.

CORREAS, Carlos M. Multiculturalismo y Derechos Humanos: las propuestas liberals y el iusnaturalismo realista. In: Multiculturalismo e universalismo de los derechos humanos. Buenos Aires: Ad-Hoc, 2008.

FERRARA, Francesco. Interpretação e aplicação das leis. 2. ed. Ed. Saraiva, 1940.

FERREIRA FILHO, Manoel Gonçalves. Direitos humanos fundamentais. 7. ed. São Paulo: Saraiva, 2005. 
GADAMER, Hans-Georg. Verdad y método I: fundamentos de una hermenêutica filosófica. 5. ed. Salamanca: Ediciones Sígueme, 1993.

HÄBERLE, Peter. Hermenêutica constitucional: a sociedade aberta dos intérpretes da constituição: contribuição para a interpretação pluralista e procedimental da Constituição. Sergio Antonio Fabris Editor. Porto Alegre, 1997.

OLIVEIRA JÚNIOR, José Alcebíades. (Org.). Faces do multiculturalismo: teoria, política e direito. Santo Ângelo: EDIURI, 2007.

PEREZ LUÑO, Antonio Enrique. Derechos humanos, estado de derecho y constitucion. 5. ed. Madrid: Tecnos, 2005.

PINTO, Mónica. Temas de derechos humanos. Buenos Aires: Editores Del Puerto, 1997.

QUEIROZ, Cristina M. M. Direitos fundamentais. Coimbra: Coimbra editora, 2002.

RAWLS, John. O direito dos povos. São Paulo: Martins Fontes, 2001.

RAZ, Joseph. Multiculturalism: a liberal perspective. In: Ethics in the Public Domain. Essays in the Morality of Law and Politics. Oxford: Clarendon Press, 1996. 